\title{
NEAR-CRITICAL WATER HYDROTHERMAL TRANSFORMATION OF INDUSTRIAL LIGNINS TO HIGH VALUE PHENOLICS
}

\author{
Weikun Jiang, † Gaojin Lyu, * $\neq$ Shubin Wu, * † Lucian A. Lucia $\neq$ \\ ${ }^{\dagger}$ State Key Lab of Pulp \& Paper Engineering, South China University of Technology, Guangzhou, \\ Guangdong 510640, People's Republic of China \\ $\$$ Key Lab of Pulp \& Paper Science and Technology of the Ministry of Education, Qilu University of \\ Technology, Jinan, Shandong 250353, People’s Republic of China
}

\begin{abstract}
A process for the production of high-value-added phenolics following hydrothermal depolymerization of black liquor lignins after acidification without catalysis was successfully deployed and is described herein. A high yield of liquid products up to $33.3 \mathrm{mg} / \mathrm{mL}$ (based on raw black liquor) was recovered at $290{ }^{\circ} \mathrm{C}, 30 \mathrm{~min}$, and $\mathrm{pH} 6$; meanwhile, only $12.6 \mathrm{mg} / \mathrm{mL}$ solid residue was obtained. GC-MS analyses of the liquid products confirmed value-added aromatic monomers, among which the yields of phenol, guaiacol, and 2, 6-dimethoxy-phenol were high $(\sim 60 \%$ of the identified compounds). FT-IR of the solid residues indicated that the black liquor lignin was depolymerized through cleavage of ether bonds and decarboxylation. The results suggest that black liquor may be a new resource for aromatic products.
\end{abstract}

Keywords: Black liquor lignin; Near-critical water; Phenolic compounds;

Quantitative analysis 


\section{Introduction}

Natural gas, fossil oil, and coal are non-renewable resources that are widely used for the production of fuels and chemicals [1]. However, public awareness of environmental pollution and energy costs have prompted the consideration of biomass as a more sustainable resource. After chitin and the cellulosics (including hemicelluloses), lignin is the most abundant biosynthesized biomass that is derived from the polymerization of three phenylpropane monomers, namely $p$-coumaryl alcohol, coniferyl alcohol, and sinapyl alcohol mainly crosslinked by $\beta-\mathrm{O}-4$ linkages $[2,3]$. Because of its unique structure and chemical properties, lignin can be considered an alternative raw material for the production of phenol, guaiacol, catechol, and syringol etc. $[4,5]$.

Lignin has been shown to be able to be converted into smaller molecular units (phenolic compounds) by hydrothermal conversion, pyrolysis, enzymatic degradation, photocatalysed degradation, electrochemical degradation, ionic liquids degradation, microwave irradiation oxidation, etc. However, the extraction of lignin is necessary and poses a nontrivial challenge. Farag and Chaouki performed an economic evaluation of converting lignin into chemicals and found that the estimated selling price was not competitive with fossil fuel-based analogues, a result primarily attributable to the high cost of the lignin feedstock [6]. In addition, expensive catalysts hinder further upgrading of lignin. 
In chemical pulping, the separation of lignin from wood chips takes place in digesters. Lignin and other organic acids are dissolved into the digester pulping liquor and leave as black liquor at a solid concentration of 15-20 wt.-\% [6]. Unfortunately, end-of-pipe discharge to receiving waters causes horrible pollution and soil contamination [7]. In fact, it has already been confirmed that alkali lignin from the black liquor can be extracted and converted into aromatic chemicals by hydrothermal treatment; a process that involves hot compressed water as a green reaction medium [8-12]. However, very little attention on direct hydrothermal decomposition of black liquor has been shown due to the complexity of the chemical constituents. If a pre-process for black liquor is added to remove adventitious impurities, using black liquor instead of lignin as feedstock for hydrothermal decomposition addresses the environmental impacts associated with papermaking and facilitates upgrading lignin for phenolic products.

First of all, the needed inorganic chemicals for the pulping process are recoverable by burning the solid product in hydrothermal decomposition [13]; it has been reported that the solid product is a high-energy char for fuel production [12]. Secondly, the needed energy for drying lignin in the precipitation and extraction process is saved. Thirdly, the inorganic salt from black liquor can play a catalytic role in the hydrothermal conversion process $[14,15]$. Most of all, the bio-oils which are mostly aromatics can be collected from the hydrothermal decomposition step. 
Herein, it is demonstrated that (Figure 1) black liquor lignin can be used as the substrate feedstock without extra catalysts. The object of the work, therefore, is to obtain high-value-added phenolics from black liquor under hydrothermal conditions. This study investigated the effect of reaction temperature $\left(200-380{ }^{\circ} \mathrm{C}\right)$, reaction time (0-120 min), and $\mathrm{pH}(2-12)$ on product distributions and yields. Products were characterized by gas chromatography mass spectroscopy (GC-MS) and fourier transform infrared spectroscopy (FT-IR).

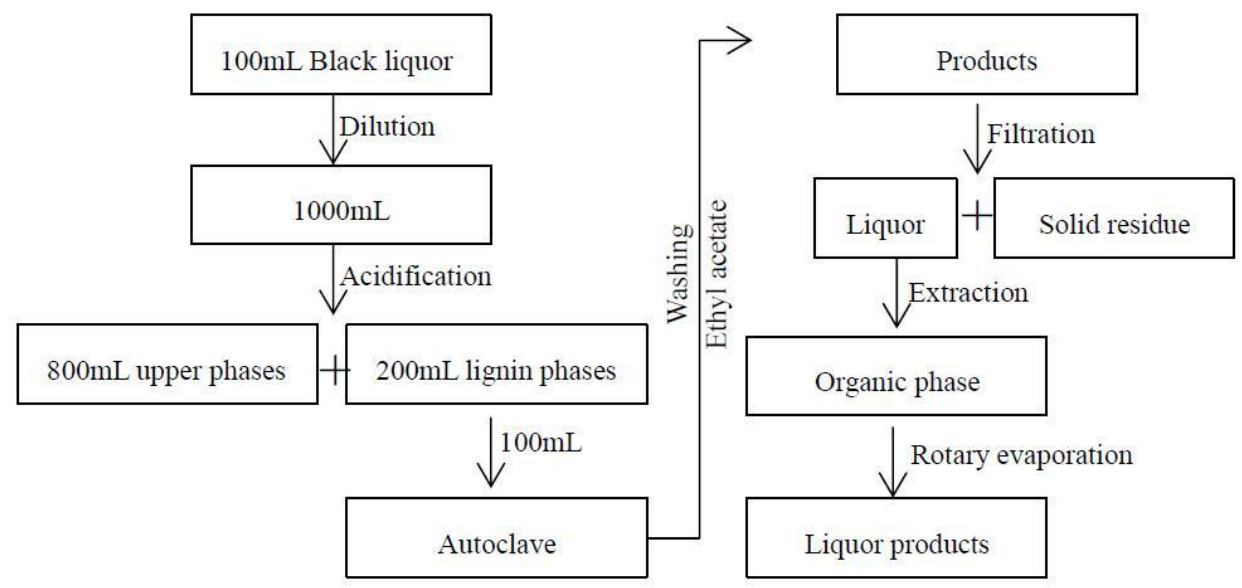

Figure 1. Schematic representation of the process used in the current study.

\section{Materials and methods}

\subsection{Materials}

All starting materials were purchased from Sinopharm Chemical Reagent Co., Shanghai (China) and used as received without further purification, unless otherwise noted. Black liquor was obtained from in-house poplar sulfate pulping. The chemical composition of products from poplar-based pulping has been previously reported [16]. In summary, its density is $1.005 \mathrm{~g} / \mathrm{mL}$ and the total solids content, organic substances, 
inorganic substances, total alkali content, and total available alkali are $15.43 \%, 8.39 \%$, $6.32 \%, 3.87 \%$, and $1.54 \%$, respectively. In addition, $1 \mathrm{~mL}$ of raw black liquor gave 63 mg alkali lignin and $24 \mathrm{mg}$ polysaccharide, which was determined by the method described by Crawford and Pometto [17]. After cooking, black liquors were collected from the reaction vessel. Then black liquor was filtered through a Buchner funnel under vacuum to facilitate solid impurities removal, of which $100 \mathrm{~mL}$ was diluted to $1000 \mathrm{~mL}$. Later, 50\% (wt.-\%) sulfuric acid was slowly added until $\mathrm{pH}=2$ was reached causing the lignin to precipitate. After precipitation, the black liquor had two distinct phases: aqueous phase and lignin phase. The visual appearance of the former was light yellowish whereas the latter was brown. The upper layer $(800 \mathrm{~mL}$, contained $300 \mathrm{mg}$ acid-soluble lignin and $1950 \mathrm{mg}$ polysaccharide) and the lignin phase (200 mL, contain $5700 \mathrm{mg}$ lignin and $370 \mathrm{mg}$ polysaccharide) were the substrate feedstock for subsequent experiments.

\subsection{Hydrothermal conversion}

The experiments were performed in a high-pressure autoclave with a 4848 Reactor Controller (Parr Instrument Company, America). The $250 \mathrm{~mL}$ batch reactor was equipped with a pressure gauge (0-5000 psi), a pressure relief valve, and a thermocouple. Typically, $100 \mathrm{~mL}$ lignin phase were transferred into the reactor. The system was vented with nitrogen three times to remove air. For each experiment, the reactor was heated at a rate of $10{ }^{\circ} \mathrm{C} / \mathrm{min}$ from ambient to $200-380{ }^{\circ} \mathrm{C}$, after which the experiment was continued for $0-120 \mathrm{~min}$. The accuracy of the temperature controller 
was $\pm 5{ }^{\circ} \mathrm{C}$. The content was stirred continuously at $100 \mathrm{rpm}$ during hydrothermal treatment. Because the acid nature of the lignin phase could pose metallurgical issues, this study investigated the effect of $\mathrm{pH}$ on the distribution and yield of various products. Herein, different substrate feedstocks (acidic, neutral, and alkaline conditions by the addition $2 \mathrm{~mol} / \mathrm{L}$ sodium hydroxide to lignin phases) were examined.

\subsection{Products separation}

The products can be separated into a liquid product (LP), a solid residue (SR), and gas. At the end of the experiment, the gas was removed from the reactor after the autoclave cooled. Gas products, mainly $\mathrm{CH}_{4}, \mathrm{CO}_{2}, \mathrm{CO}$ and $\mathrm{H}_{2}$, were collected by a latex rubber inflatable device for a GC with a Flame Ionization Detector (FID) and Thermal Conductivity Detector (TCD). Gas compositions were similar, and the yields $(<5 \%)$ were not discussed. The mixture of liquid contents was filtered with a pre-weighed G3 funnel, and filtered with a polytetrafluoroethylene (PTFE) membrane. A solid residue was oven dried at $105{ }^{\circ} \mathrm{C}$ overnight before weighing. This water-ethyl acetate liquid fraction was subjected to an extraction process. Sodium sulfate anhydrous was added to the obtained ethyl acetate liquid to remove water. Then the ethyl acetate liquor was filtered and the solvent was removed by rotary evaporation. The conversion yields of various products were calculated based on raw black liquor. The term 'LP' was used to represent the liquid products after rotary evaporation and 'SR' represented the solid residue after hydrothermal conversion. 


\subsection{Solid contents and residues analysis}

Elemental analyses of $\mathrm{C}, \mathrm{H}, \mathrm{N}, \mathrm{O}$ and $\mathrm{S}$ contents in black liquor, lignin phases, and alkali lignin samples were performed in a Vario Micro analyzer (EL III, Germany). Metal elemental analyses of $\mathrm{Cu}, \mathrm{Fe}, \mathrm{Mg}, \mathrm{K}, \mathrm{Na}, \mathrm{Ca}$ were determined on inductively coupled plasma (Optima 2000DV, American PE) using the $\mathrm{HNO}_{3}-\mathrm{HClO}_{4}$ digestion method [18].

FT-IR spectroscopy were recorded on a SHIMADZU FTIR spectrophotometer (IR Prestige-21, Japan) using a $\mathrm{KBr}$ pellet containing $\sim 1 \%$ sample over a range of 4000 to $500 \mathrm{~cm}^{-1}$.

2.5 Qualitative and quantitative analysis of the liquid products

Qualitative examination of the liquid products was performed on a GC-MS (Shimadzu QP 2010, Shimadzu, Japan) equipped with a SHRXI-5 MS capillary column $(30 \mathrm{~m} \times 0.25 \mathrm{~mm} \times 0.25 \mu \mathrm{m})$. Helium was used as the carrier gas at a flow rate of $1 \mathrm{~mL} / \mathrm{min}$. The $\mathrm{GC}$ oven temperature for analysis was: $50{ }^{\circ} \mathrm{C}$ held for $2 \mathrm{~min}$ raised at a rate of $10{ }^{\circ} \mathrm{C} / \mathrm{min}$ to $160{ }^{\circ} \mathrm{C}$; held for $2 \mathrm{~min}$; raised to $250{ }^{\circ} \mathrm{C}$ at a rate of $10{ }^{\circ} \mathrm{C} / \mathrm{min}$; and held at this final temperature for $2 \mathrm{~min}$. The injector temperature was $250{ }^{\circ} \mathrm{C}$ with a split ratio of $50: 1$. The mass selective detector was operated with an electron impact (EI) ionization mode. The data were analyzed using a NIST library. 
From the results of qualitative analysis, the main phenolic compositions with high content (based on peak area-\%) in the liquid products were identified. The dominant substances were phenol, guaiacol, 3-methylguaiacol, 3-methoxycatechol, 3-ethylguaiacol, 4-methylcatechol, 1,2,3-trimethoxy-benzene, 2,6-dimethoxyphenol, vanillin, 1,2,4-trimethoxybenzene, 4-(2-propenyl)-guaiacol, 5-methyl-1,2,3-trimethoxybenzene, and 4-hydroxy-3,5-dimethoxy-phenylethanone, which were all subsequently quantified by an external standard method. Standard compounds of these major compositions were purchased from Sigma-Aldrich. Total phenolic compounds were calculated as follows: the main phenolic compounds were accurately quantified using an external standard, while the other phenolic compounds were quantified assuming a response factor of 1.0 compared to guaiacol. All quantified aromatics yield was expressed as $\mathrm{mg} / \mathrm{mL}$ of the raw black liquor that used for depolymerization reaction.

\section{Results and Discussion}

\subsection{Identification of solid content}

The elemental analyses of three samples (solid content from raw black liquor and lignin phases, alkali lignin) are provided in Table S1. The solid content of original black liquor or separated lignin phase had a higher content of inorganics such as sodium, potassium, and calcium (the total inorganic contents were above 20\%) compared to alkali lignin. In pulping, a mixture liquor of sodium sulfite and sodium hydroxide was cooked; thus, the sodium salts in the black liquor were high. The three samples typically contained $2.0-3.2 \%$ sulfur in organically bound forms which could 
be a particularly challenging substrate for catalytic processing, especially with noble metal catalysts that are frequently poisoned by sulfur [19]. Nevertheless, it was reported that the presence of sodium salts can promote decomposition of alkali lignin, and enhance phenolic compounds [20].

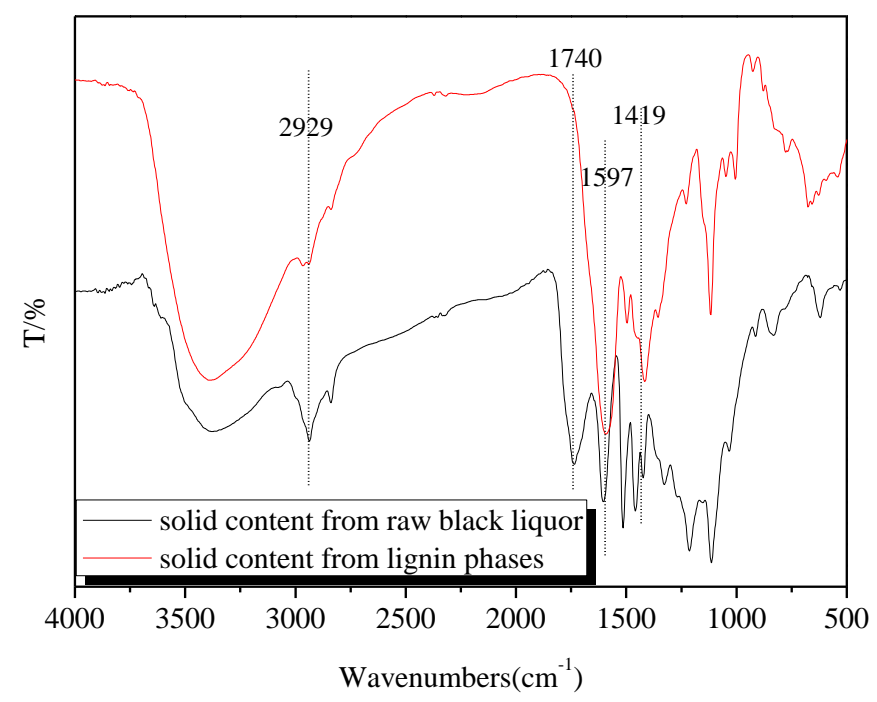

Figure 2. FT-IR spectra of the samples over $4000-500 \mathrm{~cm}^{-1}$.

Figure 2 shows the FT-IR spectra of the two samples (black liquor solid and lignin phase solid) over $4000-500 \mathrm{~cm}^{-1}$. The solid composition in the black liquor is complex: hydrocarbons, cellulose, hemicellulose, lignin, inorganic and decomposition products from cooking [21]. Thus, their spectral signatures displayed a significant difference with alkali lignin. Typical patterns of lignin at 1597 and $1419 \mathrm{~cm}^{-1}$ were observed in two samples, but the absorption peak of solid from lignin phases was more evident. The aromatic ring of the conjugate ester (lactone) absorption disappeared in $1740 \mathrm{~cm}^{-1}$ due to acid. Also, the solid content from the lignin phases 
showed a weaker absorption at $2929 \mathrm{~cm}^{-1}$ (aliphatic $\mathrm{C}-\mathrm{H}$ stretch). These results indicated that these lignin phases following acidification showed lower sugar content, which resulted in a significantly increased lignin purity.

3.2 Yield

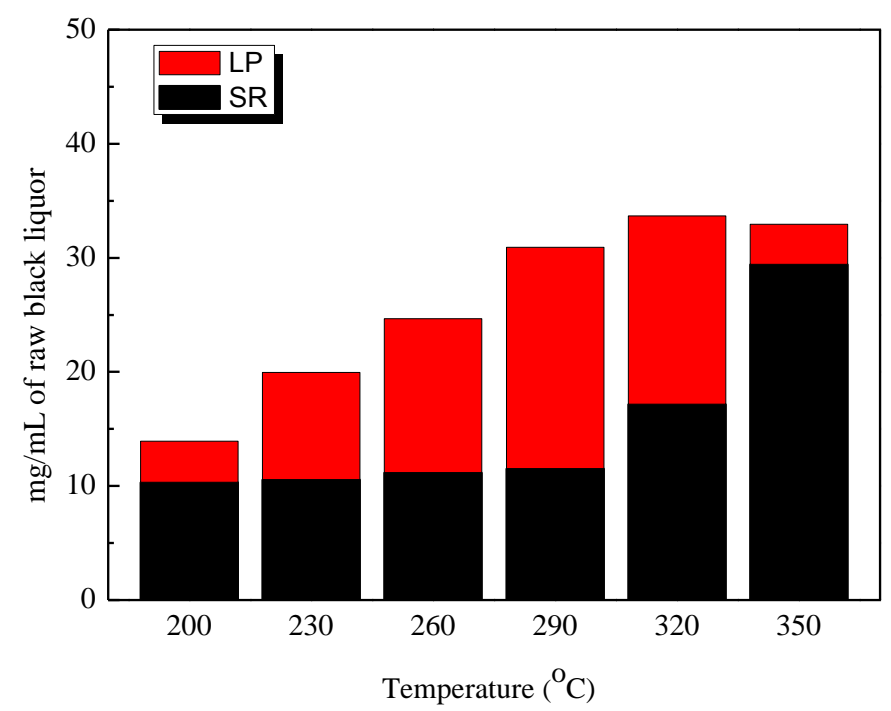

Figure 3. Effect of reaction temperature on product yields. Reaction conditions:

substrate feedstock $(100 \mathrm{~mL}, \mathrm{pH}=2)$, temperature $\left(200-350^{\circ} \mathrm{C}\right)$, reaction time $30 \mathrm{~min}$.

Figure 3 shows that temperature $\left(200\right.$ to $350{ }^{\circ} \mathrm{C}$ ) had an effect on the yield. The LP yield increased at first and later decreased with temperature increase, showing a maximum yield of $19.4 \mathrm{mg} / \mathrm{mL}$ at $290^{\circ} \mathrm{C}$. The SR yield increased slowly from 10.3 $\mathrm{mg} / \mathrm{mL}$ at $200{ }^{\circ} \mathrm{C}$ to $11.5 \mathrm{mg} / \mathrm{mL}$ at $290{ }^{\circ} \mathrm{C}$, then increased markedly to $29.4 \mathrm{mg} / \mathrm{mL}$ over 290 to $350{ }^{\circ} \mathrm{C}$. Ye et al. [5] reported that raising temperature would simultaneously promote decomposition of lignin and repolymerization of the intermediates. Such a result suggested that depolymerization reactions are more 
dominant at lower temperature $\left(<290{ }^{\circ} \mathrm{C}\right)$, while repolymerization reactions are more dominant at higher temperatures. Thus, chemical reactions are enhanced from 200 to $290{ }^{\circ} \mathrm{C}$ in black liquor. The greatly reduced LP yield after $290{ }^{\circ} \mathrm{C}$ may be explained by formation of SR through side reactions such as repolymerization of lignin-degraded intermediates. Thus, it may be concluded that $290{ }^{\circ} \mathrm{C}$ is the optimal temperature for hydrothermal conversion black liquor lignin in near-critical water.

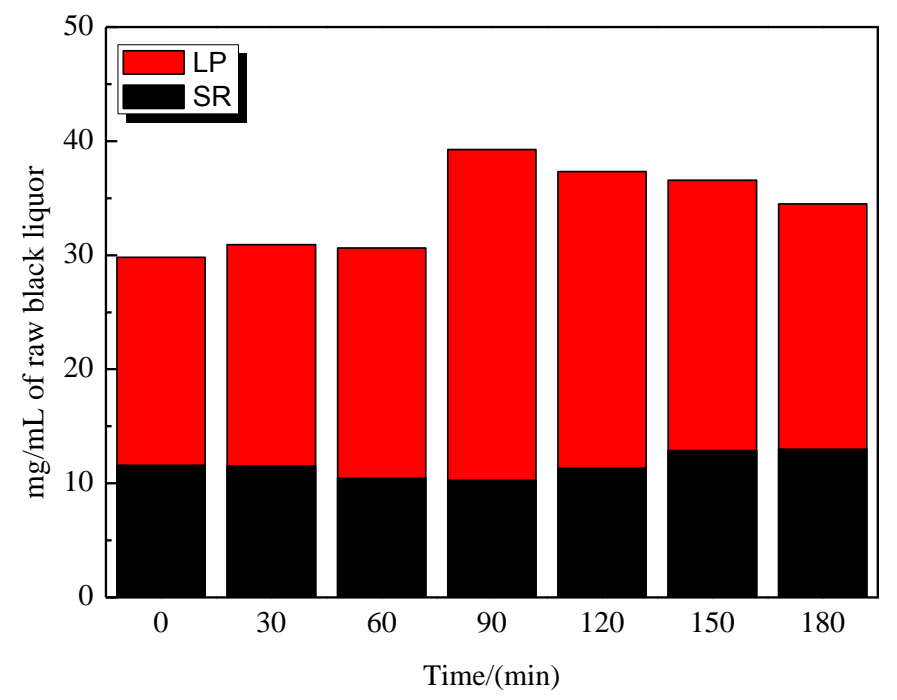

Figure 4. Effect of residence time on product yields. Reaction conditions: substrate feedstock $(100 \mathrm{~mL}, \mathrm{pH}=2)$, temperature $\left(290^{\circ} \mathrm{C}\right)$, reaction time $0-120 \mathrm{~min}$.

The influence of residence time on the distribution of products was also investigated at $290{ }^{\circ} \mathrm{C}$ as shown in Figure 4. After 90 min, the highest LP yield was close to 29.0 $\mathrm{mg} / \mathrm{mL}$ and decreased slowly to $21.5 \mathrm{mg} / \mathrm{mL}$ at a hold time of $180 \mathrm{~min}$. The SR yield decreased and then increased with reaction time with a minimum yield of $10.3 \mathrm{mg} / \mathrm{mL}$ at 90 min. During lignin degradation, cracking and condensation reactions occur simultaneously. After a certain reaction time when most of the easily cleaved bonds in 
lignin such as ether bonds and carbonyl groups were cracked, lignin depolymerization was essentially considered complete. By further increasing the residence time, the condensation of the degraded lignin intermediates occurred which accounted for SR yield increase beyond $90 \mathrm{~min}$.

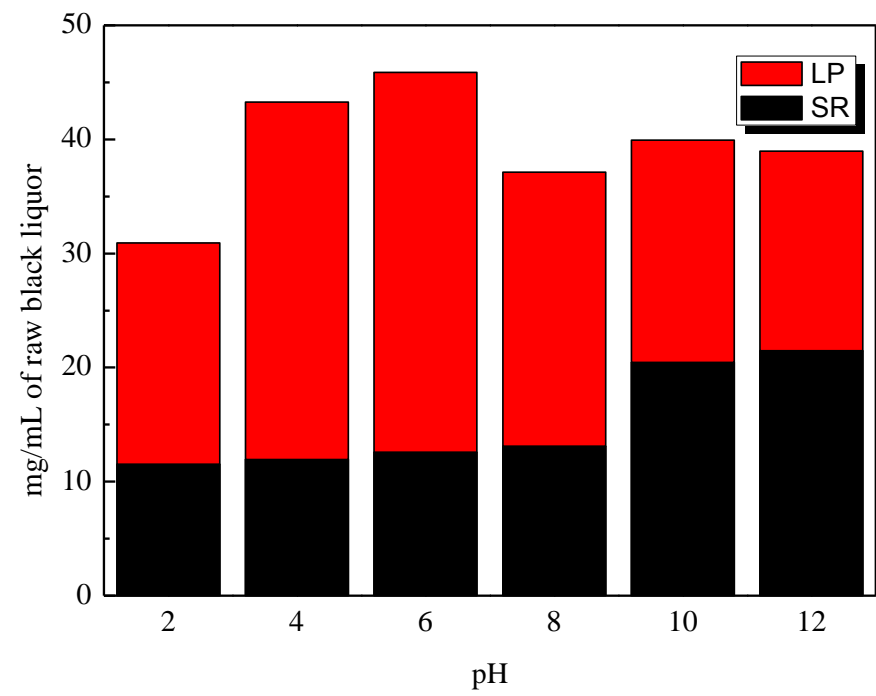

Figure 5. Effect of acid and alkali property in the solution on product yields. Reaction conditions: substrate feedstock ( $100 \mathrm{~mL}, \mathrm{pH}=2,4,6,8,10$ and 12), temperature $\left(290{ }^{\circ} \mathrm{C}\right)$, and reaction time $=30 \mathrm{~min}$.

During lignin extraction, acidification or water washing reduced the alkalinity in the black liquor and influenced lignin depolymerization. Figure 5 shows the yields of SR and LP from lignin depolymerization in a series of pHs at $290{ }^{\circ} \mathrm{C}$ and $30 \mathrm{~min}$. The substrate feedstock was adjusted to $\mathrm{pH} 2,4,6,8,10$, and 12 by sodium hydroxide. When the $\mathrm{pH}$ increased from 2 to 12 , the SR yields greatly increased from 11.5 to $21.5 \mathrm{mg} / \mathrm{mL}$. The LP yield increased with increasing $\mathrm{pH}$. However, the LP yields decreased significantly from 33.3 to $17.5 \mathrm{mg} / \mathrm{mL}$ with decreasing $\mathrm{pH}$ from 6 to 12 . It 
could be observed that the highest LP yield $(33.3 \mathrm{mg} / \mathrm{mL})$ was obtained at $\mathrm{pH} 6$.

The experimental results suggested that the presence of acid could inhibit condensation of coke. There were two reasons that explain the effect of acid on lignin depolymerization: (1) the addition of alkali helped dissolve lignin and lignin degraded intermediates so more lignin was involved and more intermediates condensed to increase the SR yields; (2) the hydrogen-donor ability of the acid lead to the stabilization of the free radicals from lignin depolymerization, which inhibited the condensation of intermediates and reduced the formation of high molecular weight compounds. In addition, the phenolic hydroxyls were replaced by sodium (to make it soluble in water), which resulted in a decrease of phenolic compounds in ethyl acetate.

3.3 Qualitative analysis of aromatic monomers

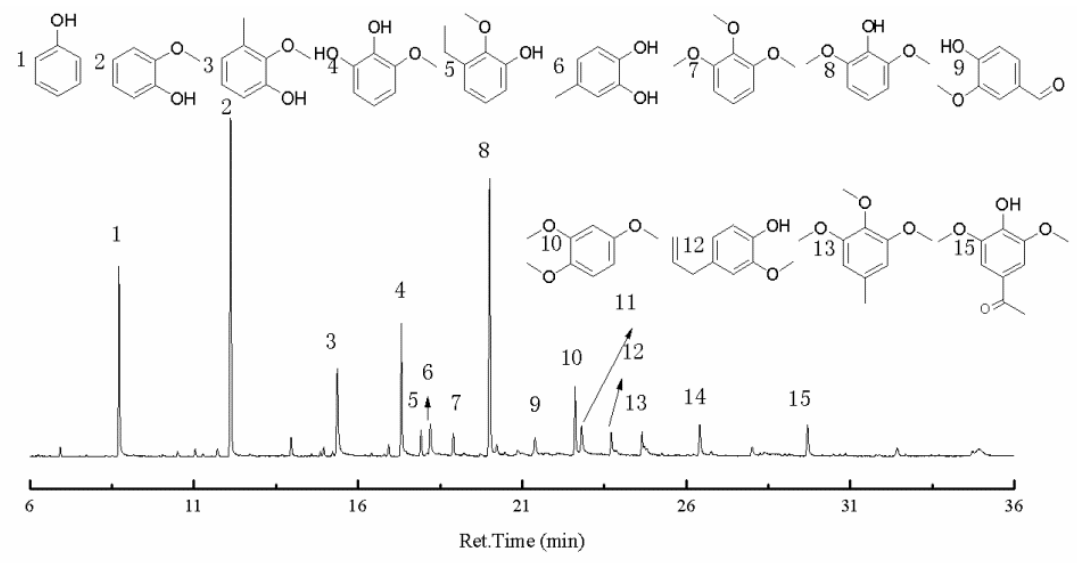

Figure 6. GC-MS chromatogram of liquor oil obtained at $290{ }^{\circ} \mathrm{C}, \mathrm{pH}=6$ and $30 \mathrm{~min}$. 
The chemical composition of the liquid products obtained was investigated by GCMS. A representative chromatogram of the product mixture obtained at $290{ }^{\circ} \mathrm{C}, \mathrm{pH}=6$ and 30 min is shown in Figure 6 and relative peak area percentages are listed in Table 1. It was not surprising that the liquid products are mainly phenolics. Interestingly, the GC-MS trace is not complex - it only showed 15 main components. All of these major products were identified in Figure 6. Most of these phenolics were valuable pharmaceutical intermediates such as phenol, guaiacol, 3-ethylguaiacol, 3-methoxycatechol and 3-methylguaiacol. The compounds could be divided into four categories: phenol-type $(\mathrm{H})$, such as phenol; guaiacol-type $(\mathrm{G})$, such as 2, 3, 4, 5, 6, 9, 10 and 12 in Figure 6; syringol-type (S), such as 7, 8, 13, and 15 in Figure 6; and others $(\mathrm{O})$.

The three most abundant products are phenol, guaiacol, and 2, 6-dimethoxyphenol with peak area-\% of $8.90,16.67$ and $13.64 \%$, respectively. The other monomers include 6.87\% 3-methylguaiacol, 7.45\% 3-methoxycatechol, 3.07\% 4-methylcatechol, etc. The three most significant products agreed with previous reports [22] on lignin hydrothermal depolymerization in water, but the peak area-\% was different, in which phenol, guaiacol and 2, 6-dimethoxyphenol accounted for 5.48\%, 20.1\% and 31.2\% of the total peak area, respectively. Contrasting the product distribution, more catechols (such as 3-methoxycatechol and 4-methylcatechol) were obtained from black liquor lignin in which the total peak area- $\%$ reached $10.52 \%$, while 3-methoxycatechol was obtained as the only catechol in $2.08 \%$ yield from lignin 
hydrothermal depolymerization [22]. The inclusion of inorganic salt may have a positive influence on the yields of low-weight monomer content, which were further demethylated to catechols. Accordingly, high-value-added phenolics can be produced from black liquor lignin depolymerization.

Table 1. Identification of main aromatic compounds from ethyl acetate soluble oil in GC-MS (Reaction conditions: $290{ }^{\circ} \mathrm{C}, \mathrm{pH}=6$ for $0.5 \mathrm{~h}$ )

\begin{tabular}{|c|c|c|c|}
\hline NO. & R. Time & Main Components & Peak area\% \\
\hline 1 & 8.717 & Phenol & 8.90 \\
\hline 2 & 12.117 & Guaiacol & 16.67 \\
\hline 3 & 15.367 & 3-Methylguaiacol & 6.87 \\
\hline 4 & 17.325 & 3-Methoxycatechol & 7.45 \\
\hline 5 & 17.917 & 3-Ethylguaiacol & 1.38 \\
\hline 6 & 18.200 & 4-Methylcatechol & 3.07 \\
\hline 7 & 18.900 & 1,2,3-Trimethoxybenzene & 1.43 \\
\hline 8 & 20.008 & 2,6-Dimethoxyphenol & 13.64 \\
\hline 9 & 21.392 & Vanillin & 1.66 \\
\hline 10 & 22.617 & 1,2,4-Trimethoxybenzene & 3.81 \\
\hline 11 & 22.817 & Dimethyl Phthalate (plasticizer) & 2.93 \\
\hline 12 & 23.325 & 4-(2-Propenyl)-guaiacol & 1.95 \\
\hline 13 & 23.725 & 5-Methyl-1,2,3-trimethoxybenzene & 1.39 \\
\hline 14 & 24.658 & Diethyl Phthalate (plasticizer) & 2.43 \\
\hline
\end{tabular}




\subsection{Quantitative analysis of aromatic monomers}

The distribution of different aromatic products (mainly as guaiacol-type (G), syringol-type $(\mathrm{S})$, phenol-type $(\mathrm{H})$ and others $(\mathrm{O})$ ) from black liquor lignin depolymerization is shown in Figures 7, 8 and 9, and detailed quantified monomer yields are shown in the Supplementary Data (Table S2-S4).

Table S2 shows the changes between the phenolic chemicals from black liquor lignin depolymerization under $230,260,290,320,350$, and $380{ }^{\circ} \mathrm{C}$. The results showed phenol, guaiacol, catechol, 3-methoxycatechol, 2, 6-dimethoxyphenol and 4-hydroxy-3, 5-dimethoxyphenylethanone are the main compounds; it was observed that the amount of the guaiacol, catechol, and 3-methoxycatechol increased and then decreased with temperature. The maximum amounts of guaiacol $(0.71 \mathrm{mg} / \mathrm{mL})$, catechol $(0.45 \mathrm{mg} / \mathrm{mL})$, and 3-methoxycatechol $(0.74 \mathrm{mg} / \mathrm{mL})$ were obtained at $320^{\circ} \mathrm{C}$. As the temperature increases, phenol and 2, 6-dimethoxyphenol yield showed the same change trend as guaiacol, while the maximum yield $(0.87$ and $0.94 \mathrm{mg} / \mathrm{mL})$ was obtained at $290{ }^{\circ} \mathrm{C}$, and quickly decreased to 0.22 and $0.02 \mathrm{mg} / \mathrm{mL}$ with an increase to $340{ }^{\circ} \mathrm{C}$. In addition, some compounds were not found within a specific temperature range. Catechol and 4-methylcatechol, for example, were relatively more abundant in the higher temperature runs; whereas syringaldehyde, 4-hydroxy-3, 
5-dimethoxyphenylethanone, 4-propylguaiacol and anisole were relatively more abundant at lower temperature. The yields of 4-hydroxy-3, 5-dimethoxyphenylethanone continually declined from 0.38 to $0 \mathrm{mg} / \mathrm{mL}$ with temperature increase. It was considered that guaiacol were the precursors that decomposed for the formation of catechol [23]. It suggested that the secondary cracking reactions (especially the demethylation reaction) of those products were promoted under higher temperatures, a result in good agreement with the hydrothermal conversion of alkali lignin [22], where less syringol and guaiacol were detected at high temperatures.

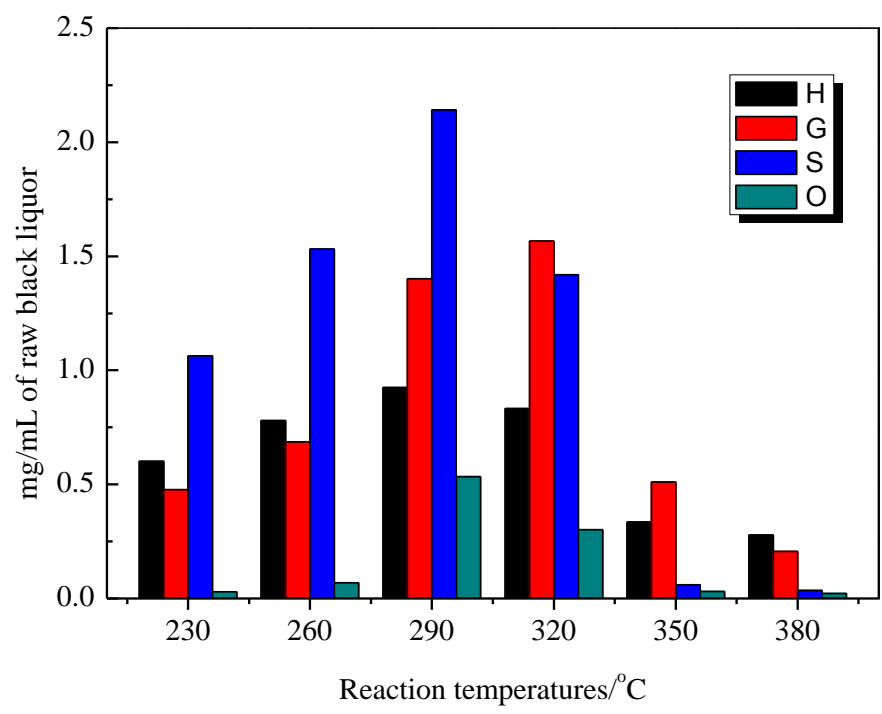

Figure 7. Effect of reaction temperature on aromatic product yields (Reaction conditions: $100 \mathrm{~mL}$ substrate feedstock $(\mathrm{pH}=2)$, temperature $\left(230-380{ }^{\circ} \mathrm{C}\right)$, reaction time $30 \mathrm{~min})$.

Besides analyzing the yields of different mono aromatics, it is also interesting to examine the overall yield (guaiacol-type (G), syringol-type (S), phenol-type (H) and 
others $(\mathrm{O})$ ) of aromatic compounds (Figure 7). The overall yield increased as the reaction temperature increases from $220{ }^{\circ} \mathrm{C}$ to $290{ }^{\circ} \mathrm{C}$. In particular, a large increase was found for total guaiacol-type compounds increased from 0.48 to $1.57 \mathrm{mg} / \mathrm{mL}$, total syringol-type compounds increased from 1.06 to $2.14 \mathrm{mg} / \mathrm{mL}$, and total other compounds (O) from 0.03 to $0.53 \mathrm{mg} / \mathrm{mL}$. Slight differences were total phenol-type compounds yield from 0.60 to $0.92 \mathrm{mg} / \mathrm{mL}$ until to $320^{\circ} \mathrm{C}$.

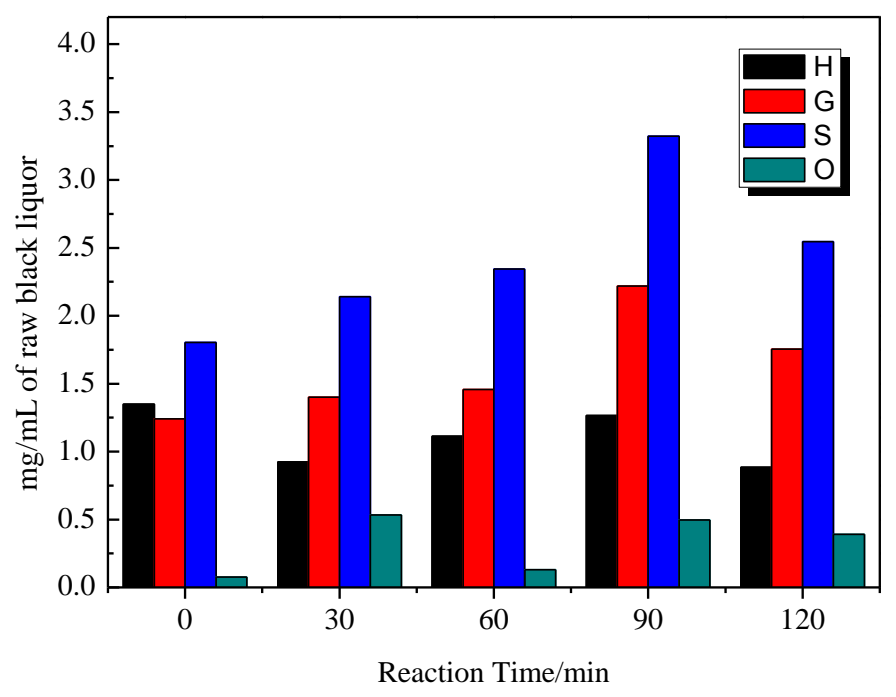

Figure 8. Effect of reaction time on aromatic product yields (Reaction conditions: 100 $\mathrm{mL}$ substrate feedstock $(\mathrm{pH}=2)$, temperature $\left(290^{\circ} \mathrm{C}\right)$, reaction time $\left.0-120 \mathrm{~min}\right)$.

The yields of phenolic chemicals with varied reaction times are presented in Table S3 and Figure 8. It is clear that increasing residence time to $90 \mathrm{~min}$, the total yield of G-type and S-type compounds increased significantly (from 1.24 to 2.24 and 1.80 to $3.32 \mathrm{mg} / \mathrm{mL}$, respectively), whereas the changes in total yields of H-type compounds were less marked. Obviously, there were more S-type related compounds than G-type and H-type compounds under any reaction time. However, further prolonging 
residence time to $120 \mathrm{~min}$ resulted in a slight reduction of the yield of the S-, G- and H-type compounds. Significant changes were further observed at prolonged reaction times. The concentration of 3-methoxycatechol and 2, 6-dimethoxyphenol increased with residence time increasing, but the yield of 4-hydroxy-3, 5-dimethoxyphenylethanone decreased markedly (from 0.51 to $0.03 \mathrm{mg} / \mathrm{mL}$ ) at longer residence times. Meanwhile, the yields of phenol and guaiacol varied to a very little degree. In short, the composition of the LP varied with the different residence times. Longer residence time $(90 \mathrm{~min})$ favored formation of simple compounds such as 4-methylphenol, guaiacol, 2-ethylphenol, catechol, 3-methoxycatechol, 4-ethylcatechol, and 4-methylcatechol. The results summarized in Table S3 indicated that short reaction time $(0-60 \mathrm{~min})$ was not sufficient for black liquor lignin conversion and long reaction time (>90 $\mathrm{min}$ ) favored further decomposition of already degraded lignin intermediates.

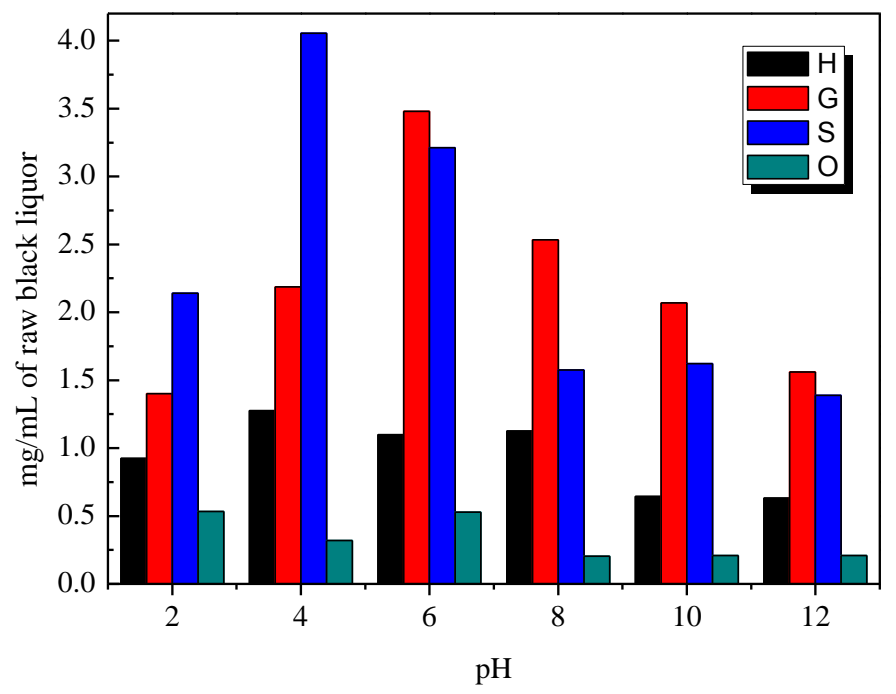

Figure 9. Effect of acidic, neutral, and alkaline conditions on aromatic product yields (Reaction conditions: $100 \mathrm{~mL}$ substrate feedstock ( $\mathrm{pH}=2,4,6,8,10$ and 12), 
temperature $\left(290{ }^{\circ} \mathrm{C}\right)$, reaction time $\left.30 \mathrm{~min}\right)$.

Next, the effect of $\mathrm{pH}$ on LP yields for the hydrothermal degradation of black liquor lignin was investigated. Table S4 shows the results of the quantitative examination of the phenolic compounds obtained from hydrothermal decomposition of black liquor lignin, while Figure 9 provides the distribution of H-, G- and S-type phenolic compounds under different $\mathrm{pH}$. It was observed that the amount of the G- and S-type phenolic compounds increased and then decreased with $\mathrm{pH}$ increasing. The maximum amount of G-type phenolic compounds $(3.48 \mathrm{mg} / \mathrm{mL})$ and S-type phenolic compounds $(4.06 \mathrm{mg} / \mathrm{mL})$ was obtained at $\mathrm{pH}=6$ and 4 as shown in Figure 9. In the products obtained under $\mathrm{pH}=2$ and 4 , the dominant phenolics were $\mathrm{S}$-type compounds, such as 2, 6-dimethoxy-phenol, 1, 2, 3-trimethoxy-5-methyl-benzene, 1, 2, 3-Trimethoxy-5-methyl-benzene, etc. When $\mathrm{pH}$ increased, the total S-type compounds reduced and tended to become stable between 1.39 and $1.57 \mathrm{mg} / \mathrm{mL}$, and the dominant substances became G-type compounds. With $\mathrm{pH}$ increasing, the quantity of many products reached a maximum. When substrate $\mathrm{pH}=4$, the highest yield of phenol and 2, 6-dimethoxyphenol was 1.22 and $2.48 \mathrm{mg} / \mathrm{mL}$. When substrate $\mathrm{pH}=6$, guaiacol $(1.80 \mathrm{mg} / \mathrm{mL}), 3$-methoxycatechol $(0.80 \mathrm{mg} / \mathrm{mL}), 4$-methylcatechol $(0.33$ $\mathrm{mg} / \mathrm{mL}), 1,2$, 4-trimethoxybenzene $(0.41 \mathrm{mg} / \mathrm{mL})$ reached a maximum. The highest yield of 4-methylguaiacol $(0.52 \mathrm{mg} / \mathrm{mL})$ and catechol $(0.84 \mathrm{mg} / \mathrm{mL})$ was obtained at pH 8 and 10, respectively. 
3.5 FT-IR analysis of solid residues

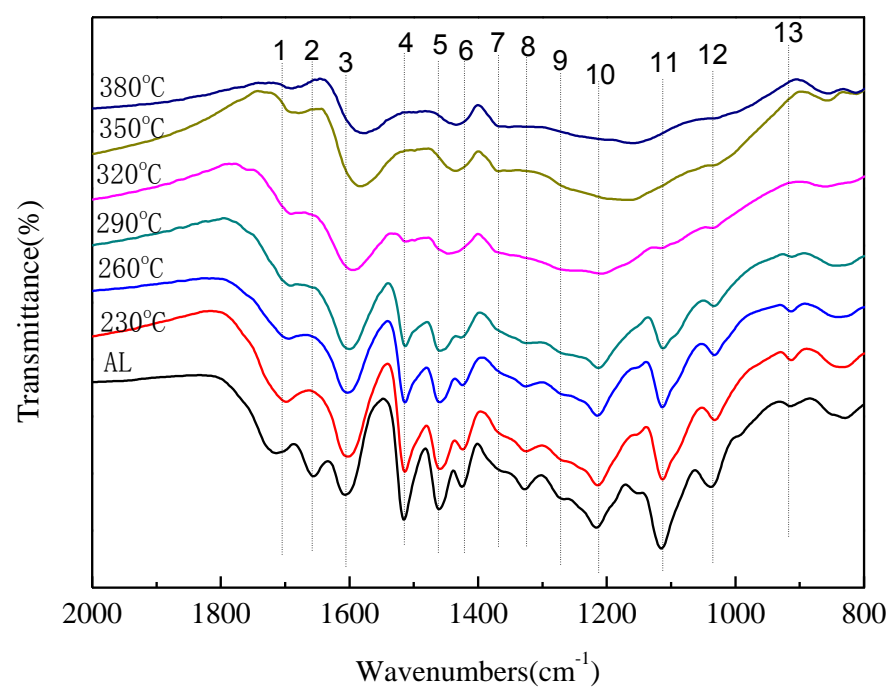

Figure 10. FT-IR spectra of alkali lignin and the SR after different temperatures.

The FT-IR spectra of alkali lignin from black liquor and the SR are shown in Figure 10. The relevant peaks were identified according to previous work [24, 25]. As expected, the absorbance from the ether bond $\mathrm{C}-\mathrm{O}-\mathrm{C}$ at 1325 (8), 1270 (9), 1113 (10), 1120 (11) and $1034 \mathrm{~cm}^{-1}$ (12) weaken in intensity for SR with increasing reaction temperature, which is due to the breakage of $\beta-\mathrm{O}-4$ or/and $\alpha-\mathrm{O}-4$ ether bonds to form hydroxyl groups and alkyl groups. The declining absorbance at 1604 (3), 1514 (4), and $1425 \mathrm{~cm}^{-1}$ (5) that are attributed to aromatic nuclei indicate that aromatic rings in lignin and lignin degraded intermediates carbonized to form SR. The weakened absorbance at $1700 \mathrm{~cm}^{-1}$ (1) implies that decarboxylation occurred more strongly with increasing temperature. The diminishing absorbance at $1660 \mathrm{~cm}^{-1}$ (2) implies that the breakage of the coumaryl ether groups or aldehyde groups occurred 
even at $230{ }^{\circ} \mathrm{C}$. These results indicate that SR consisted of organic material with a composition of minimal pyrolyzed lignin at low temperatures and a highly carbonized material at high temperatures [26]. When the temperature exceeded $290{ }^{\circ} \mathrm{C}$, the organic constituents of lignin in SR largely disappeared.

Similar efforts examining the effect of temperature $\left(220-340{ }^{\circ} \mathrm{C}\right)$ on the SR from alkali lignin hydrothermolysates were previously reported [22]. For alkali lignin, as the temperature increased, these SR samples also showed a stepwise drop in intensity of the aromatic $\mathrm{O}-\mathrm{H}$ bands. However, the solid residue until $340{ }^{\circ} \mathrm{C}$ displayed nearly no aromatic $\mathrm{O}-\mathrm{H}$ bands. Lignin in black liquor needed lower temperature or less energy for conversion because of the presence of inorganics.

\section{Conclusions}

This work successfully investigated a method for the hydrothermal degradation of black liquor lignin for high-value-added phenolic compounds. The GC-MS analysis showed that these compounds were mainly phenols, guaiacols, catechols, and syringols. The yields of LP and SR were markedly dependent upon the reaction temperature and the $\mathrm{pH}$ of feedstock, whereas the residence time had only a slight influence. Lower temperature or less energy was needed during the hydrothermal conversion of black liquor lignin compared to alkali lignin as the feedstock. A large number of compounds even low-weight monomers could be produced in relatively mild conditions. In addition, the highest yields were obtained under different 
hydrothermal conditions, whereas $1 \mathrm{~mL}$ of raw black liquor gave $1.31 \mathrm{mg}$ phenol, $2.48 \mathrm{mg}$ 2, 6-dimethoxyphenol, $1.80 \mathrm{mg}$ guaiacol, $0.80 \mathrm{mg}$ 3-methoxycatechol, 0.33 mg 4-methylcatechol, $0.52 \mathrm{mg} 4-\mathrm{methylguaiacol}$, and $0.84 \mathrm{mg}$ catechol. This process may prove to be significant for valorization of lignin feedstock for the production of renewable chemicals in a biorefinery construct.

\section{Corresponding Authors}

*Tel.: +86 531 89631681. Fax: +86 531 89631630. E-mail: gaojinlv@qlu.edu.cn (G. Lyu);

*Tel.: +86 20 22236808. Fax: +86 20 22236808. E-mail: shubinwu@scut.edu.cn (S. $\mathrm{Wu})$

\section{Acknowledgements}

The authors are grateful for financial support from the National Key Basic Research Program of China (No. 2013CB228101), the National Science Foundation of China (No. 31400517, 31270635), the Science Foundation of Shandong Province (BS2013NJ014), the Open Foundation of SKLPPE (No. 201437), and the Taishan Scholars Project Special Funds. 


\section{References}

[1] N.T.D. Huyen, M. Maschietti, L.E. Amand, L. Vamling, L. Olausson, S.I. Andersson, $\mathrm{H}$. Theliander, The effect of temperature on the catalytic conversion of Kraft lignin using near-critical water, Bioresour. Technol. 170 (2014) 196-203. Doi:10.1016/j.biortech.2014.06.051.

[2] J. Zakzeski, P.C.A. Bruijnincx, A.L. Jongerius, B.M. Weckhuysen, The catalytic valorization of lignin for the production of renewable chemicals, Chem. Rev. 110 (2010) 3552-3599. Doi: 10.1021/cr900354u.

[3] C.A. Chen, H. Pakdel, C. Roy, Production of monomeric phenols by thermochemical conversion of biomass: a review, Bioresour. Technol. 79 (2001) 277-299. Doi:10.1016/S0960-8524(00)00180-2.

[4] P.D. Wild, R.V.D. Laan, A. Kloekhorst, E. Heeres, Lignin valorisation for chemicals and transportation fuels via catalytic pyrolysis and hydrodeoxygenation, Environ. Prog. Sustain. 28 (2009) 461-469. Doi: 10.1002/ep.10391.

[5] Y. Ye, Y. Zhang, J. Fan, J. Chang, Novel method for production of phenolics by combining lignin extraction with lignin depolymerization in aqueous ethanol, Ind. Eng. Chem. Res. 51 (2012) 103-110. Doi: 10.1021/ie202118d.

[6] S. Farag, J. Chaouki, Economics evaluation for on-site pyrolysis of kraft lignin to value-added chemicals, Bioresour. Technol. $175 \quad$ (2015) 254-261. Doi:10.1016/j.biortech.2014.10.096.

[7] D. Shen, J. Zhao, R. Xiao, S. Gu, Production of aromatic monomers from catalytic 
pyrolysis of black-liquor lignin, J. Anal. Appl. Pyrolysis. 111 (2015) 47-54. Doi: 10.1016/j.jaap.2014.12.013.

[8] J. Hu, R. Xiao, D. Shen, H. Zhang, Structural analysis of lignin residue from black liquor and its thermal performance in thermogravimetric-fourier transform infrared spectroscopy, Bioresour. Technol. 128 (2013) 633-639. Doi:10.1016/j.biortech.2012.10.148.

[9] J.A. Onwudili, Influence of reaction conditions on the composition of liquid products from two-stage catalytic hydrothermal processing of lignin. Bioresour. Technol, 187 (2015) 60-69. Doi:10.1016/j.biortech.2015.03.088.

[10] H. Pinkowska, P. Wolak, A. Zlocinska, Hydrothermal decomposition of alkali lignin in sub- and supercritical water, Chem. Eng. J. 187 (2012) 410-414. Doi:10.1016/j.cej.2012.01.092.

[11] X. Zhou, Conversion of kraft lignin under hydrothermal conditions, Bioresour. Technol. 170 (2014) 583-586. Doi: 10.1016/j.biortech.2014.08.076.

[12] S. Kang, X. Li, J. Fan, J. Chang, Solid fuel production by hydrothermal carbonization of black liquor, Bioresour. Technol. 110 (2012) 715-718. Doi:10.1016/j.biortech.2012.01.093.

[13] N.T.D. Huyen, M. Maschietti, T. Belkheiri, L.E. Amand, H. Theliander, L. Vamling, L. Olausson, S.I. Andersson, Catalytic depolymerisation and conversion of kraft lignin into liquid products using near-critical water, J. Supercrit. Fluids. 86 (2014) 67-75. Doi:10.1016/j.supflu.2013.11.022. 
[14] T. Bhaskar, A. Sera, A. Muto, Y. Sakata, Hydrothermal upgrading of wood biomass: influence of the addition of $\mathrm{K}_{2} \mathrm{CO}_{3}$ and cellulose/lignin ratio, Fuel 87 (2008) 2236-2242. Doi:10.1016/j.fuel.2007.10.018.

[15] S. Sun, H. Li, X. Cao, F. Xu, R. Sun, Structural variation of eucalyptus lignin in a combination of hydrothermal and alkali treatments, Bioresour. Technol. 176 (2015) 296-299. Doi:10.1016/j.biortech.2014.11.030.

[16] C. Zhang, Y. Liu, Componential analysis of black liquor and determining of dissolution lignin, Paper Paper Making. 1 (2012) 63-64.

[17] R.L. Crawford, A.L. Pometto, Methods in Enzymology, Academic Press Inc., San Diego. 1988.

[18] Y. Sun, L. Chen, J. Zhao, Y. Lu, Comparison of acid digestion methods for the determination of heavy metals in municipal sludge, Chinese Agricultural Science Bulletin 26 (2004) 170-173.

[19] C. Li, X. Zhao, A. Wang, G.W. Huber, T. Zhang, Catalytic transformation of lignin for the production of chemicals and fuels, Chem. Rev. 115 (2015) 11559-11624. Doi: 10.1021/acs.chemrev.5b00155.

[20] D. Guo, S. Wu, B. Liu, X. Yin, Q. Yang, Catalytic effects of $\mathrm{NaOH}$ and $\mathrm{Na}_{2} \mathrm{CO}_{3}$ additives on alkali lignin pyrolysis and gasification, Appl Energy 95 (2012) 22-30. Doi:10.1016/j.apenergy.2012.01.042.

[21] R. Chandra, A. Abhishek, Bacterial decolorization of black liquor in axenic and mixed condition and characterization of metabolites, Biodegradation 22 (2011) 
603-611. Doi: 10.1007/s10532-010-9433-1.

[22] W. Jiang, G. Lyu, Y. Liu, C. Wang, J. Chen, L.A. Lucia, Quantitative analyses of lignin hydrothermolysates from subcritical water and water-ethanol systems, Ind. Eng. Chem. Res. 53 (2014) 10328-10334. Doi: 10.1021/ie5011178.

[23] W.T. Kanetake, M. Sasaki, M. Goto, Decomposition of a lignin model compound under hydrothermal conditions, Chem. Eng. Technol. 30 (2007) 1113-1122. Doi: 10.1002/ceat.200700066.

[24] O. Faix, Classification of lignins from different botanical origins by FT-IR spectroscopy, Holzforschung 45 (1991) 21-28. Doi: 10.1515/hfsg.1991.45.s1.21.

[25] S.Y. Lin, C.W. Dence, Methods in lignin chemistry, Springer-Verlag, Berlin, 1992.

[26] R. Lou, S. Wu, Products properties from fast pyrolysis of enzymatic/mild acidolysis lignin, Appl Energy 88 (2011) 316-322. Doi: 10.1016/j.apenergy.2010.06.028. 